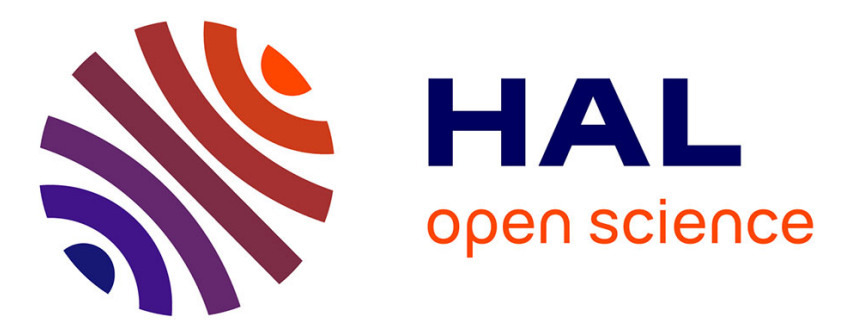

\title{
Maternal omega-3 status: effects of cross-fostering on offspring brain lipids and hippocampal neurogenesis
}

Christine Heberden, Elise Maximin

\section{To cite this version:}

Christine Heberden, Elise Maximin. Maternal omega-3 status: effects of cross-fostering on offspring brain lipids and hippocampal neurogenesis. Omega Fatty Acids in Brain and Neurological Health, 2eme ed., Academic Press, 518 p., 2019, 9780128152386. 10.1016/C2017-0-01595-1 . hal-02788945

\section{HAL Id: hal-02788945 \\ https://hal.inrae.fr/hal-02788945}

Submitted on 5 Jun 2020

HAL is a multi-disciplinary open access archive for the deposit and dissemination of scientific research documents, whether they are published or not. The documents may come from teaching and research institutions in France or abroad, or from public or private research centers.
L'archive ouverte pluridisciplinaire HAL, est destinée au dépôt et à la diffusion de documents scientifiques de niveau recherche, publiés ou non, émanant des établissements d'enseignement et de recherche français ou étrangers, des laboratoires publics ou privés. 


\section{Provided for non-commercial research and educational use. Not for reproduction, distribution or commercial use.}

This chapter was published in the book Omega Fatty Acids in Brain and Neurological Health published by Elsevier, and the attached copy is provided by Elsevier for the author's benefit and

for the benefit of the author's institution, for non-commercial research and educational use including without limitation use in instruction at your institution, sending it to specific colleagues who you know, and providing a copy to your institution's administrator.

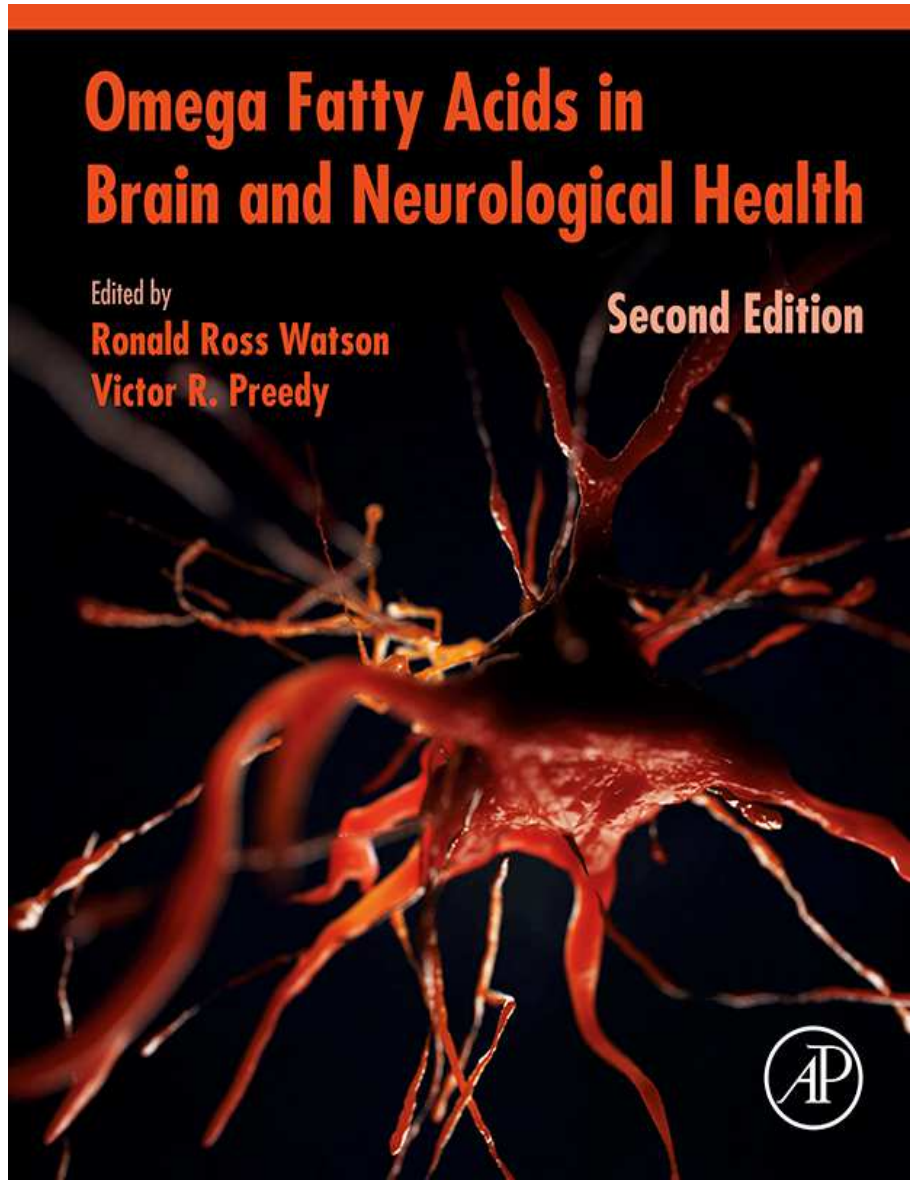

All other uses, reproduction and distribution, including without limitation commercial reprints, selling or licensing copies or access, or posting on open internet sites, your personal or institution's website or repository, are prohibited. For exceptions, permission may be sought for such use through Elsevier's permissions site at:

\section{https://www.elsevier.com/about/our-business/policies/copyright/permissions}

Elise Maximin and Christine Heberden, Maternal Omega-3 Status: Effects of Cross-Fostering on Offspring Brain Lipids and Hippocampal Neurogenesis. In: Ronald Ross Watson and Victor R. Preedy (eds.) Omega Fatty Acids in Brain and Neurological Health. Burlington: Academic Press, 2020. pp. 193-198.

ISBN: 978-0-12-815238-6

(C) 2019 Elsevier Inc. All rights reserved. 


\section{2}

\section{Maternal Omega-3 Status: Effects of Cross-Fostering on Offspring Brain Lipids and Hippocampal Neurogenesis}

Elise Maximin, Christine Heberden

Micalis Institute INRA, Jouy-en-Josas, France

\section{INTRODUCTION}

Omega- 3 and -6 fatty acids ( $\omega 3$ or $n-3 ; \omega 6$ or $n-6$ ) are necessary components of the brain, and diet is the main supplier of these essential lipids. Because the main source of n-3 fatty acids comes from seafood in western societies, a deficiency in n-3 is now highly widespread. It is considered that a balanced diet should supply a daily ratio of $n-6 / n-3$ equal to 5 , whereas nutritional studies show that the actual ratio in most developed countries is around 15 . Many studies have focused on this problem, and preclinical studies have shown that n-3 in low amounts and n- 6 in high proportions are detrimental to cerebral physiology and structures. ${ }^{1}$

This is especially important in infants. Indeed the synthesis capacities of the fetus and infants are very limited. In the early phases of life, the fetus and infants are entirely dependent on the maternal diet and the maternal stores during either pregnancy or the lactating period. ${ }^{2}$

Maternal supplementation in omega 3 translates into numerous benefits for the children. Indeed, the children born to supplemented mothers, or fed a diet supplemented in n-3 are more attentive and less hyperactive. ${ }^{3}$ The reports showing a positive effect on IQ have been questioned though. ${ }^{4-6}$

Interestingly, the benefits of a n-3-rich diet on the children are not only immediate, but can be recorded for during several years in the childhood. ${ }^{3}$ Preclinical models have shown consistent data: omega-3 supplementation proved protective toward emotional behavior, cognition, and neurogenesis in rodents. ${ }^{7-10}$

The supplementation is also necessary and beneficial to the mothers; indeed, under inadequate omega-3 supply, the maternal docosahexaenoic acid (DHA) stores are depleted under 
a single reproductive cycle in the rat. ${ }^{11}$ In humans as well as in rodents, n-3 maternal supplementation improves the mood of the expectant mothers and prevents the development of postpartum depression. ${ }^{12,13}$

The omega-3 molecular action mechanisms are not fully unveiled, but several studies have pointed to the modification of gene transcriptions ${ }^{14}$ or DNA methylation. ${ }^{15}$ The latter study suggests that omega 3 induce epigenetic effects, which have been also described in other studies. ${ }^{16}$ For instance, we have shown that in vitro neural stem cells (NSCs) derived from pups born to deficient or supplemented mothers behave differently in vitro displaying a higher rate of proliferation, higher maturation, and modifications of gene expressions. ${ }^{17}$

In this report, we have questioned whether the dietary environment of pups born to omega-3 deficient or supplemented mothers could impact the proportions of PUFA in brain lipids and the rate of hippocampal neurogenesis in the adult offspring.

\section{METHODS}

Male Wistar rats bred in our own facilities were used for this experiment. Female rats were fed 2 weeks before mating with one of the two following diets: the "deficient" diet provided $0.01 \%$ of the total energy as linoleic acid $(5 \mathrm{mg} / 100 \mathrm{~g}$ diet), and the "supplemented" diet provided high levels of DHA ( $1.0 \%$ of the total energy, $500 \mathrm{mg} / 100 \mathrm{~g}$ diet). The diets contained $6.6 \mathrm{~g}$ lipids $/ 100 \mathrm{~g}$ and were prepared using mixtures of rapeseed, sunflower, and tuna fish oils, kindly provided by Lesieur (Asnières-sur-Seine, France). ${ }^{18}$

Before the pups were 1-week old, the litters were allocated to surrogate mothers, so that all the dams would adopt pups from another female. The sizes of the litters were similar for all the surrogate mothers $(n=6)$. Therefore, the pups were separated into four groups: (i) born to a supplemented mother, adopted by a supplemented mother (noted $\omega 3-\omega 3$ ), (ii) born to a supplemented mother, adopted by a deficient mother ( $\omega 3-\omega 6)$, (iii) born to a deficient mother, adopted by a deficient dam ( $\omega 6-\omega 6)$, and (iv) born to a deficient mother, adopted by a supplemented one $(\omega 6-\omega 3)$.

After weaning, the offspring was fed the same diet as the surrogate dams up until 4 months of age, and were maintained in a comforting environment, at 2 per cage to avoid the stress of isolation. Three days before the sacrifice, they were intraperitoneally injected daily with $50 \mathrm{mg} / \mathrm{kg}$ BrdU dissolved in $0.007 \mathrm{~N} \mathrm{NaOH}$ in PBS $(10 \mathrm{mg} / \mathrm{mL})$. They were euthanized by decapitation and the brains were rapidly removed. The cerebellum was excised and saved for lipid analysis and the rest was rapidly frozen in chilled isopentane and kept at -80 degree until analysis.

The fatty acid compositions of the two main classes of membrane PLs, the ethanolamine-phosphoglycerolipids (EPGs) and phosphatidylcholine (PC), were analyzed by gas chromatography, as previously described. ${ }^{1}$

Brains were sectioned at $16 \mu \mathrm{m}$ with a cryostat and the sections were revealed for BrdU presence in the cells by immunohistochemistry as described before. ${ }^{19}$ The cells positive for BrdU in the dorsal hippocampus were counted using Image J.

Statistical analyses for lipid analyses and neurogenesis were performed in GraphPad prism by one- or two-way ANOVA (followed by Tukey's multiple comparisons). The results are expressed as mean $\pm \mathrm{SD}$. Results were significantly different at $P<.05$. 


\section{RESULTS}

The pups' weights at birth were similar $(6 \pm 0.5 \mathrm{~g})$ regardless of the mothers' diet. At 4 months, the rats' weights were not significantly different even though the animals born to deficient dams and fed with high proportions of $\omega 3$ were a little heavier: $\omega 3-\omega 3: 564 \pm 22 \mathrm{~g} ; \omega 3-\omega 6$ : $546 \pm 41 \mathrm{~g} ; \omega 6-\omega 6: 548 \pm 38 \mathrm{~g} ; \omega 6-\omega 3: 611 \pm 62.9 \mathrm{~g}$.

The cerebellum were excised from the brains, and analyzed for the fatty acid compositions in EPG and PC.

Figs. 1 and 2 show abbreviated data from the fatty acid analyses for EPG and PC, respectively: total n-6 and n-3 have been shown, along with 20:4 n-6 (arachidonic acid, AA) and 22:6 n-3 (DHA) since AA and DHA are the main fatty acid from each family.

In EPG, statistical analysis showed that $\omega 3-\omega 3$ and $\omega 6-\omega 3$ are not statistically different; the levels of total n-3 and DHA are restored in pups born to deficient mothers by higher proportions offered by the lactation and diet after weaning. This result shows that a diet

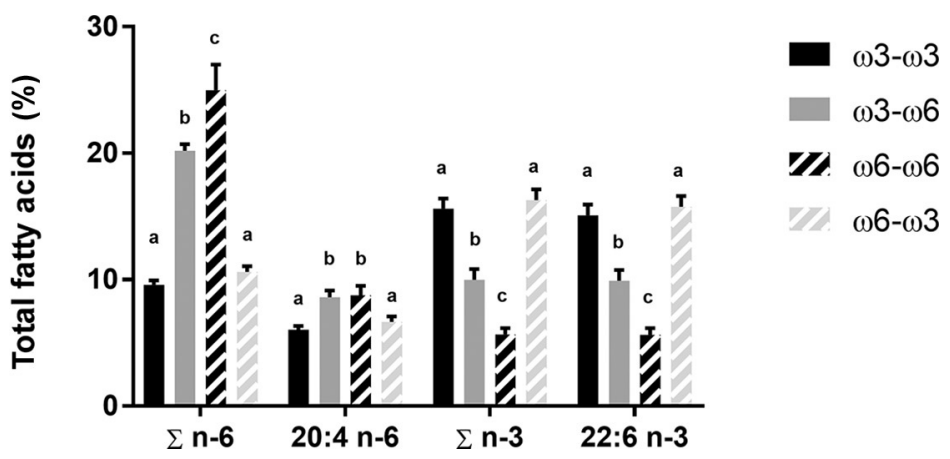

FIG. 1 Modifications of the percentages of polyunsaturated fatty acids in the EPG fraction. For each group, six cerebellums were collected and analyzed by gas chromatography. Different superscripts denote a significant difference at $P<.05$.

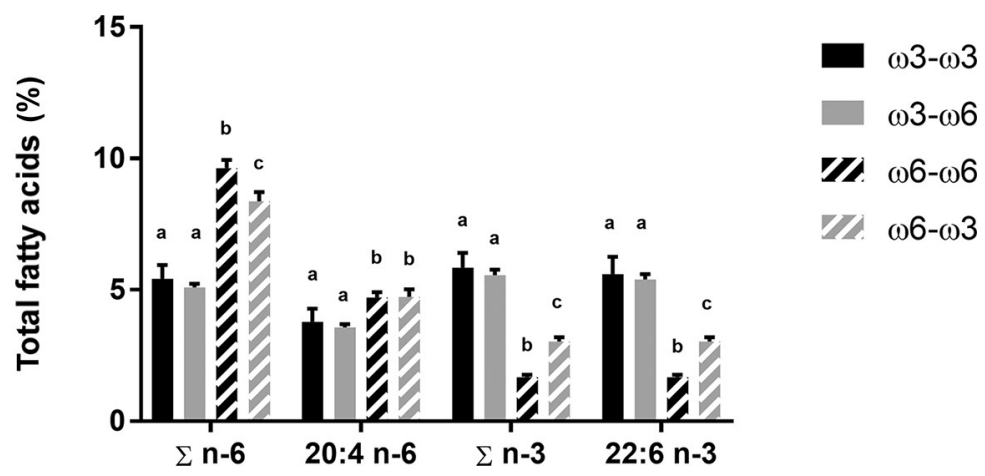

FIG. 2 Modifications of the percentages of polyunsaturated fatty acids in the PC fraction. For each group, six cerebellums were collected and analyzed by gas chromatography. Different superscripts denote a significant difference at $P<.05$. 


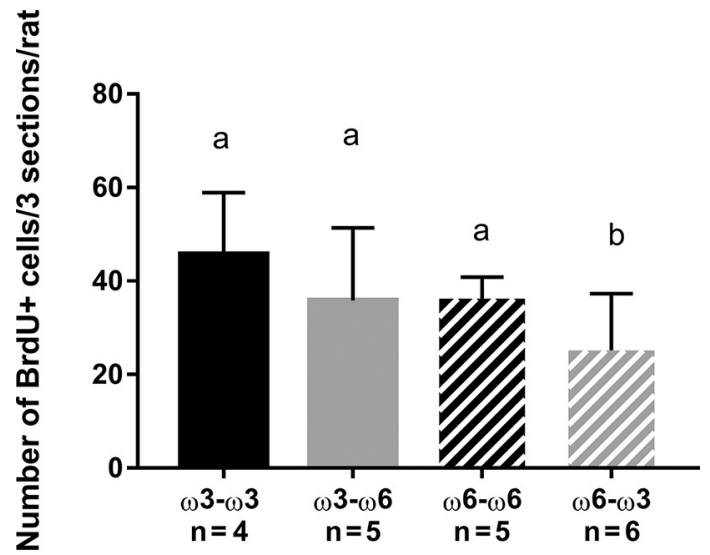

FIG. 3 Number of cells positive for BrdU in the dentate gyrus of the dorsal hippocampus. Immunohistochemistry was performed and for each animal, cells from three consecutive sections were counted. Different superscripts denote a significant difference at $P<.05$.

supplemented as early as the lactating period was able to reverse the deficiency noted in $\omega 6-\omega 6$ animals. Indeed this group was deeply depleted in $\omega 3$.

In PC, total $\omega 3$ and DHA percentages obtained in $\omega 3-\omega 3$ offspring were similar to the ones obtained in the $\omega 3-\omega 6$ animals, but interestingly, total $\omega 3$ and DHA in $\omega 6-\omega 3$ animals remained lower than in animals born to supplemented mothers and fed the supplemented diet ( $\omega 3-\omega 3)$. This shows that $\omega 3$ supply at lactation and further could enhance the proportions of 22:6 n-3, but not to a level equivalent to the one registered in EPG and could not totally counteract the deficit created in utero.

To analyze the rate of hippocampal neurogenesis, the rats were injected with BrdU, and cells positive for BrdU were counted.

Fig. 3 shows the data obtained in the dorsal hippocampus. Cells positive for BrdU tend to be less numerous in $\omega 6-\omega 6$ than in $\omega 3-\omega 3$, although the difference is not statistically significant. The $\omega 6-\omega 3$ animals had fewer positive cells than $\omega 3-\omega 3$ rats. This result shows that the level of dorsal hippocampal neurogenesis was not entirely restored by $n-3$ supplementation at lactation and by the diet.

\section{DISCUSSION}

Consistent with the data in the literature, we have shown that pups born to deficient mothers display a deficit in total $\omega 3$ and DHA in the PL, and this deficit is present in the early fetal phases. ${ }^{19}$ This deficit can be totally (EPG) or partially (PC) erased by subsequent dietary supplementation. EPG and PC are the most abundant PL species in the cell membrane, with PC in higher quantities than EPG. Therefore, the composition of the membranes in deficient animals can be modified by a lifelong $\omega 3$ supplementation but the restoration of the levels registered in animals born to supplemented mothers is not entirely complete.

The animal body growth was not affected either. 
Yet, in the hippocampus, the rate of neurogenesis was lower in animals $\omega 3$-depleted in utero, even though they were fed adequate levels of $\omega 3$ after birth.

This result seems to suggest that a critical event in the development in which $\omega 3$ are decisive, has been lacking in deficient animals.

On the other hand, $\omega 3-\omega 6$ rats that have been fed a deficient diet after birth but in utero have received an adequate level of $\omega 3$ are not impacted by the subsequent $\omega 3$ deficiency.

This is consistent with the idea that there seems to be a "window of opportunity" in the brain, as noted by Kodas et al. ${ }^{20}$ Indeed the study showed that dopaminergic neurotransmission was restored in deficient pups when $\omega 3$ were provided during lactation but not after weaning. Our result suggests that as far as neurogenesis is concerned, this window could take place even earlier.

The fact that the restoration of the levels of neurogenesis was not complete, also suggests that epigenetic effects can eventually modulate the fate of NSCs. NSCs are known to be sensitive to epigenetic effects, and we have shown that NSCs derived from deficient or supplemented pups behave differently when cultured in vitro, with higher rates of proliferation and deeper maturation once allowed to differentiate. ${ }^{17}$ Furthermore, numerous epigenetic effects have been attributed to $\omega 3$, whether they modify gene transcription through DNA methylation or miRNA synthesis. ${ }^{16}$

Therefore, our study shows that while the fatty acid compositions of membrane PL is restored by $\omega 3$ supplementation, hippocampal neurogenesis illustrates the fact that not all the consequences of $\omega 3$ deficiency in utero can be reversed by adequate levels provided after birth. Womb, birth, weaning: in the brain, these periods translate into different phases of development and "windows of opportunity." The $\omega 3$ family has proven essential in these different events.

This result argue for a very early $\omega 3$ maternal supplementation, prior to and during pregnancy.

\section{Acknowledgments}

This study was supported by a grant from the Groupe Lipides Nutrition (Neuilly-sur-Seine, France). We are indebted to Mr. P. Dahirel and Mrs. C. Maudet for excellent animal care.

\section{References}

1. Guesnet P, Alessandri JM. Docosahexaenoic acid (DHA) and the developing central nervous system (CNS)implications for dietary recommendations. Biochimie. 2011;93:7-12.

2. Haggarty P. Fatty acid supply to the human fetus. Annu Rev Nutr. 2010;30:237-255.

3. Ramakrishnan U, Gonzalez-Casanova I, Schnaas L, et al. Prenatal supplementation with DHA improves attention at 5 y of age: a randomized controlled trial. Am J Clin Nutr. 2016;104:1075-1082.

4. Helland IB, Smith L, Saarem K, Saugstad OD, Drevon CA. Maternal supplementation with very-long-chain n-3 fatty acids during pregnancy and lactation augments children's IQ at 4 years of age. Pediatrics. 2003;111:e39-e44.

5. Gale CR, Robinson SM, Godfrey KM, et al. Oily fish intake during pregnancy-association with lower hyperactivity but not with higher full-scale IQ in offspring. J Child Psychol Psychiatry. 2008;49:1061-1068.

6. Gould JF, Treyvaud K, Yelland LN, et al. Does n-3 LCPUFA supplementation during pregnancy increase the IQ of children at school age? Follow-up of a randomised controlled trial. BMJ Open. 2016;6:e011465.

7. Lozada LE, Desai A, Kevala K, Lee JW, Kim HY. Perinatal brain docosahexaenoic acid concentration has a lasting impact on cognition in mice. J Nutr. 2017;147:1624-1630. 
8. Fan C, Fu H, Dong H, Lu Y, Lu Y, Qi K. Maternal n-3 polyunsaturated fatty acid deprivation during pregnancy and lactation affects neurogenesis and apoptosis in adult offspring: associated with DNA methylation of brain-derived neurotrophic factor transcripts. Nutr Res. 2016;36(9):1013-1021.

9. Sakayori N, Tokuda H, Yoshizaki K, et al. Maternal nutritional imbalance between linoleic acid and alphaLinolenic acid increases Offspring's anxious behavior with a sex-dependent manner in mice. Tohoku J Exp Med. 2016 Sep;240(1):31-37.

10. Gao J, Wu H, Cao Y, et al. Maternal DHA supplementation protects rat offspring against impairment of learning and memory following prenatal exposure to valproic acid. J Nutr Biochem. 2016;35:87-95.

11. Levant B, Radel JD, Carlson SE. Reduced brain DHA content after a single reproductive cycle in female rats fed a diet deficient in N-3 polyunsaturated fatty acids. Biol Psychiatry. 2006;60:987-990.

12. Harauma A1, Sagisaka T2, Horii T2, et al. The influence of n-3 fatty acids on maternal behavior and brain monoamines in the perinatal period. Prostaglandins Leukot Essent Fatty Acids. 2016;107:1-7.

13. Chen HF, Su HM. Fish oil supplementation of maternal rats on an n-3 fatty acid-deficient diet prevents depletion of maternal brain regional docosahexaenoic acid levels and has a postpartum anxiolytic effect. $J$ Nutr Biochem. 2012;23:299-305.

14. Andrade-da-Costa B, Isaac A, Silva E, et al. Low omega 6/omega 3 fatty acid ratio in maternal diet favors leukemia inhibitory factor (LIF) gene transcription in the offspring's neural cells. Glia. 2017;65:E250.

15. Sable P, Randhir K, Kale A, et al. Maternal micronutrients and brain global methylation patterns in the offspring. Nutr Neurosci. 2013;18:30-36.

16. Heberden C, Maximin E. Epigenetic effects of N-3 polyunsaturated fatty acids. In: Preedy VR, Patel VB, eds. Handbook of Nutrition, Diet, and Epigenetics. Springer International Publishing AG; 2017:1-15.

17. Goustard-Langelier B, Koch M, Lavialle M, Heberden C. Rat neural stem cell proliferation and differentiation are durably altered by the in utero polyunsaturated fatty acid supply. J Nutr Biochem. 2013;24:380-387.

18. Langelier B, Linard A, Bordat C, et al. Long chain-polyunsaturated fatty acids modulate membrane phospholipid composition and protein localization in lipid rafts of neural stem cell cultures. J Cell Biochem. 2010;110:1356-1364.

19. Maximin E, Langelier B, Aioun J, et al. Fatty acid binding protein 7 and n-3 poly unsaturated fatty acid supply in early rat brain development. Dev Neurobiol. 2016;39:287-297.

20. Kodas E, Vancassel S, Lejeune B, et al. Reversibility of n-3 fatty acid deficiency-induced changes in dopaminergic neurotransmission in rats: critical role of developmental stage. J Lipid Res. 2002;43:1209-1219. 